\title{
Desirable Attributes and Practices for Mentees: Mentor Teachers' Expectations
}

\author{
Peter Hudson ${ }^{1}$ \\ ${ }^{1}$ Faculty of Education, Queensland University of Technology, Kelvin Grove, 4059, Australia \\ *E-mail: pb.hudson@qut.edu.au
}

\begin{abstract}
Research indicates attributes and practices for mentor teachers that can be used for effective mentoring. Universities provide guidelines for preservice teacher (mentee) engagement in schools generally from anecdotal evidence, however, what are desirable attributes and practices for mentees? This qualitative study gathers data from 25 mentor teachers through an extended response questionnaire and audio-recorded focus group discussions about attributes and practices for mentees. Findings showed that desirable attributes for mentees included: enthusiasm, being personable, commitment to children, lifelong learning/love of learning, open/reflective to feedback, develop resilience, and taking responsibility for their learning, while desirable practices included: planned and preparation for teaching, reflective practices; understanding school and university policies, knowing students for differentiated learning, and building a teaching repertoire (e.g. teaching strategies, behaviour management, content knowledge, and questioning skills). Preservice teachers need to consider teachers"e suggestions on desirable attributes and practices that can help them achieve positive teaching experiences.
\end{abstract}

Keywords: mentor; preservice teachers; mentoring; teaching practices; teacher training

\section{Introduction}

There is considerable research on determining mentor teacherse attributes and practices for effective mentoring. Even though universities provide guidelines and expectations for preservice teacher engagement within schools, attributes and practices for mentees needs to be considered from the perspective of the mentors, particularly as the mentee will engage in a professional relationship with the mentor. This paper presents qualitative research on what mentors may consider to be desirable attributes and practices for preservice teachers ${ }^{\text {ee }}$ to optimise their school experiences.

\section{Literature Review}

Classroom teachers (mentors) and mentees (preservice teachers) are the enactors of educational reform (Hudson, 2010). There is ample evidence that effective mentoring can have a positive effect on a preservice teacher"s pedagogical practices (Evertson \& Smithey, 2000). This evidence extends to advancing specific teaching practices such as managing students and their behaviours in classrooms (e.g. Sempowicz \& Hudson, 2011, 2012). Monaghan and Lunt (1992) suggest that mentors and mentees construct the mentor"s role through personal interaction; however in more recent years mentors have models to guide their practices as an attempt to provide more consistency to the mentoring process. Indeed, there are numerous studies that focus on the mentor (e.g. Hobson, Ashby, Malderez, \& Tomlinson 2009; Iancu-Haddad \& Oplatka, 2009; Jones \& Straker, 2006; McCann \& Johannessen, 
2009), including studies on identifying mentor's attributes and practices. For example, Hudson's (2010) mentoring model unpacks attributes and practices within five factors, namely: the mentor teacher's personal attributes, mentoring of system requirements, modelling of teaching practices, pedagogical knowledge for teaching, and feedback about teaching.

Models outlining how preservice teachers need to interact with their mentors, on the other hand, are not clearly accessible. In one sense, preservice teachers (mentees) are provided with directions from universities on how they are to engage within their school placements, which may include how they need to present themselves professionally and ways of engaging with mentors, other personnel and students within the school (e.g. for Queensland University of Technology [QUT] see http://feo.ed.qut.edu.au/). Yet there can be tensions within mentor-mentee partnerships, causes of which can include a lack of open communication and disparate beliefs about teaching, in which the "dichotomy of roles can put mentors and student teachers in a confusing and untenable position" (Bradbury \& Koballa, 2008). Understanding roles through clear expectations can assist mentees to engage more purposefully in schools.

For decades, others (Le Cornu \& Ewing, 2008; Maynard, 2000; Monaghan \& Lunt, 1992) have uncovered that mentees are concerned about how they will interact with their mentors (and others) towards achieving successful teaching experiences. There are practical indications of responsibilities for preservice teachers such as dress codes, holding a valid card to work with school students, contact information of relevant personnel, receiving mentor reports, and what to do within the classroom, such as seeking daily feedback from the mentor, taking initiative and being prepared (e.g., QUT). Some suggest broad ideas for mentees entering into a mentoring relationship such as the need to be sensitive, patient, and flexible, particularly as preservice teachers are "guests in the classroom", which requires a certain level of understanding and etiquette (Ward \& Wells, 2003, p. 42).

The research question for this study was: What are desirable attributes and practices for mentees? Specifically, this study aimed to gather perspectives from experienced teachers about preservice teachers' desirable attributes and practices. The purpose was to commence collating potential attributes and practices that may assist mentees to engage more effectively with mentor teachers when undertaking school experiences (e.g. practicum and internship).

\section{Context and Data Collection Methods and Analysis}

This qualitative study collected data from 25 experienced teachers using a written response questionnaire and audio-recorded focus groups. The questionnaire asked: (1) What attributes would you like mentees to have when they enter the school? Why? (2) (1) What practices would you like mentees to have when they enter the school? Why? Focus groups were asked to discuss their written responses from the questionnaire so deeper information around suggested attributes and practices can be analysed.

The participants included 11 secondary teachers and 14 primary teachers $(7$ males and 18 females) with 13 who had mentored between 1 to 4 mentees, 4 had mentored between 5-9 mentees, 5 had mentored 10 or more mentees and 3 who had not mentored a preservice teacher. Four participants were between the ages of 22-29 years (which included the 3 who had not mentored previously but were trained in a mentoring program), 14 were between 30-49 years and the rest older than 50 years of age. Although 4 participants had only taught between 1-4 years, the rest had taught for more than 5 years, including 13 who had taught for more than 10 years. Only seven participants had received previous mentoring professional development, which included being on a mentoring committee, a one day conference (8 years ago), Specialist Teacher Assistant Course Mentoring course in the UK, and a twoday Mentoring for Effective Teaching (MET) professional development. Five participants claimed they were in leadership positions within their secondary schools (i.e., deputy principal, head of department, 
director of learning, head of curriculum, coordinator of Indigenous education). All participants were involved in a two-day MET program (see www.tedd.net.au).

Questionnaire responses and digital audio recordings were transcribed by an experienced research assistant with a PhD. Questions focused on the personal attributes and practices needed for mentees to optimise their school (e.g., practicum and internship) experiences. Data were analysed by collating participant responses into themes with a process of coding and re-coding (Creswell, 2012). For instance, "personable" became a theme from mentor collated from words such as "personable", "compassionate", "caring", "able to develop relationships", and other qualities that develop relationships like "listening", "good communication" and having "a sense of humour". Similarly, "commitment to children" was a main theme derived from terms such as "commitment", "dedicated", "service to others", "work ethics", and "interest in children". Selected written and audio responses were used to demonstrate these themes (see Creswell, 2012).

\section{Study Findings}

\section{Mentors' Views of Desirable Mentees' Attributes}

The 25 participants' questionnaire responses provided more than one desirable mentee attribute, which were collated into these themes: enthusiasm $(n=14)$, personable for relationship building (13), commitment to children and their learning (12), lifelong learning (11), reflective on feedback (11), develop resilience (12), and taking responsibility (7). The following will elaborate further on these collated themes. As indicated, there were 14 experienced teachers who wrote "enthusiasm" as a desirable personal attribute for mentees. This enthusiasm extends to working with people and for teaching as a career choice, as illustrated by these four comments:

- Enthusiasm for teaching and working with people (Participant 9).

- To be enthusiastic - they have to want to be there, it's not just a job (Participant 10).

- Enthusiasm for chosen career - wants to be there (Participant 11).

- Enthusiasm - for job satisfaction as well as engagement (Participant 15).

Being personable for relationship building. Relationship building can be complex and as such being personable was a desirable mentee attribute indicated by 13 participants, which largely involved the notion of being social and developing relationships through personality. Being personable tended to be linked with other qualities such as being an attentive listener, a good communicator, socially confident, and having a sense of humour. To illustrate: Participant 17 wrote being "personable/ caring and considerate - being able to build authentic relationships and communicate with others" (Participant 17) with Participant 18's comment also linking being personable with building relationships, "Personable - to be able to communicate and build authentic relationships". Indeed, being personable and confident in "constructing positive relationships within the school community" (Participant 13) with a "happy personality that enjoys life and having fun" (Participant 12) appeared to be a way these participants claimed to develop positive relationships. Personality with a sense of humour tended to be a key for engaging school students as well, for example: "Personality - in order to engage students must have personality to first get their attention" (Participant 7) and they need "a sense of humour which can disarm almost all situations" (Participant 1). The ways to be personable were outlined in their comments, which included communication skills, personality traits, and being socially confident with all people (students, staff, parents, and the wider community). Rajuan, Beijaard, and Verloop (2008) outline the mentor-mentee relationship as pivotal to the working arrangements within the school and the level of mentor support. Other research (Ensher \& Murphy, 2011) has also demonstrated how a positive 
mentor-mentee relationship can maximise the level of support; thus being personable in the relationship may be a way to maximise a school experience for the mentee.

Showing commitment to children. Commitment to others, and particularly for working with children, was highlighted as a linchpin to the profession and a desirable mentee attribute. Commitment tended to be connected to developing relationships and a conscientious work ethic for teaching students, as demonstrated by the following five comments:

- Genuine interest in children gains a positive interrelationship (Participant 1).

- Enjoy working with and for younger people or children - can relate to kids (Participant 2).

- An interest in child development - crucial for planning and goal setting and ensuring learning occurs (Participant 14).

- Interest in child development - to be able to differentiate and care and want to see them grow into wonderful people (Participant 17).

- Conscientious/strong work ethic (Participant 4).

Having a "genuine interest in children" goes towards creating resilience, as the mentee has a valued-based purpose when genuinely interested in the students' learning and welfare. Although experienced teachers note this as a core attribute of being a teacher, some mentees continue to contemplate their suitability to the profession and, without a genuine interest in students, may lack the attributes required to sustain themselves in the profession.

Being lifelong learners. Eleven teachers from this cohort recognised themselves as lifelong learners and required mentees to have this desirable attribute, which further acknowledges that learning to teach does not cease after completing a university degree. Indeed, these participants highlighted the lifelong journey of learning as a way to grow and adapt to change, for instance: "to be lifelong learners - it's a journey of learning and to model it you have to do it" (Participant 10), "willingness to learn learning does not stop, we never know everything" (Participant 12), and "willing to grow and learn - so they can make changes, (being an) adaptable, lifelong learner" (Participant 15). This lifelong learning related to how teachers use their developing knowledge and skills to assist others, especially teaching school students: "A love of learning - can recognise and value self-learning and learning in others and have a service-orientated disposition - value opportunities to help others" (Participant 2). The claim was that teachers can only assist others if they are prepared to continue along the learning path themselves, necessitating a continual up-skilling in order to help others. The literature also signals lifelong learning as an action that can assist in transforming education (Longworth, 2013).

Being reflective. Being reflective was noted by nearly all these participants in varying ways, however, only 11 mentioned being reflective as a desirable mentee attribute specifically, for example: "being reflective - to be able to reflect on their own practice and the mentor's feedback" (Participant 19), "reflective - can look 'honestly' at practice and note things that worked, didn't work, were needed and why" (Participant 20), and "reflective - to be honest in self reflection and be open - to be able to take on board advice given" (Participant 21). There were several who insinuated reflectivity as part of feedback, as demonstrated by Participant 11's comment: "open to feedback - acts on feedback, accepts feedback and doesn't take it personally". As preservice teachers are in their formative stages of development, they may not have experienced "constructive feedback" if they had not been in the workforce previously. Developing a "thick skin" and "not taking it personally" may not be part of their existing framework. Constructive criticism may be seen by some preservice teachers as failing in their endeavours to become teachers; consequently resilience strategies must be developed. Yet constructive 
feedback is required for a mentee to reflect on practice and develop change strategies for pedagogical advancement (Sempowicz \& Hudson, 2011).

Being resilient. Developing resilience as a desirable mentee attribute was emphasised by 10 experienced teachers in this study. Resilience strategies were also outlined within desirable personable qualities such as they need to develop a "sense of humour - be able to laugh at oneself, situations and move on (and) courage - being able to take risks even when fearing failure or doing unknown" (Participant 3). It appeared that risk taking was considered as a creative endeavour for learning how to teach students, that is, the risk of trying something they have not attempted before, something new: "be experimental - try and be creative" (Participant 6) in order to build resilience. Yet with experimentation and risk taking there can be lessons that do not go according to plan. Hence, other resilient strategies include "flexibility - recognise and understand not all plans happen as planned, be dynamic to roll and flow" (Participant 3) coupled with knowledge to be "able to bounce back after a bad lesson or crisis" (Participant 7).

Being a role model and an initiator. There were seven comments about taking the responsibility for learning how to teach, which tended to be based around taking the initiative mentee, being a role model, and asking questions to guide their understanding about teaching, as indicated here:

- Good citizens - law abiding, moral, dutiful, etc. not only for modelling but because it's an end point of our teaching (Participant 16)

- Have an understanding of the role/responsibility of the teacher (Participant 8).

- Using intuition - seeing what makes sense, what needs to be done and acting on it (Participant $13)$.

It may appear obvious to mentor teachers that preservice teachers must be role models to the students. However, in many cases, the preservice teacher has recently completed high school and understandings about what it means to be a role model may be undeveloped, particularly if there have been adequate life experiences to guide the development of such morality. Furthermore, it may be difficult to understand the role and responsibilities of the teacher without being involved in such endeavours previously. Also a mentee who takes initiative may be going beyond the assigned responsibilities attributed to a learner in the profession; hence care must be exercised if a mentee wants to initiate an action. As pointed out earlier, the mentor-mentee partnership will be critical in how the mentee can enact a professional role with the mentee using open communication around such roles, responsibilities and initiatives to ensure these are within the boundaries of perceived actions for a preservice teacher.

\section{Mentors' Views of Desirable Mentee Practices}

The 25 teachers' extended written responses provided one or more desirable mentee practices, which were collated around these themes: planned $(n=13)$, preparation (8), evaluate teaching (7), school and university policies (6), know students for differentiated learning (5), teaching strategies (4), behaviour management (4), content knowledge (3), questioning skills (2), and observation skills (2). The evidence around mentors' views of mentees' desirable practices will be presented in more detail here.

Planning and preparation for teaching. Desirable mentee practices appeared to be linked very closely with teachers' work in schools. For instance, planning and preparation were considered as ways to achieve student outcomes with end points and negate possible issues: "Planning - not only the next lesson but the lesson as a step in a series towards an overall achievement of an outcome for the class" (Participant 7), "Being thorough in planning and forethought - able to envisage the end point and work out a plan to get there" (Participant 16), and "Initially planning the structure of the lesson and being informed about possible problems and the content - no catastrophes" (Participant 1). Importantly, many 
claimed preparation for teaching was a foundation for commencing the mentee's school experiences: "be really well-prepared for their practicum" (Participant 20).

Building a repertoire of teaching strategies.Trying new teaching strategies was signalled as way to build the teacher's repertoire of practical applications that help to achieve results, as shown by the following four comments:

- Willingness to try new/different teaching strategies - so that he/she can become adaptable and build on strengths/correct weaknesses (Participant 4).

- Teaching strategies - knowledge of and to be prepared to use various strategies to identify what works best (Participant 19).

- Work out own teaching strategies based on best practice, what works (Participant 21).

- Practical exploration/application of strategies (Participant 20).

Managing students. Behaviour management can be an issue for preservice teachers (and for experienced teachers). The mentor teacher has greater knowledge of the students and their behaviours, which allows the teacher to be more effective in utilising appropriate methods to manage students. These experienced teachers wanted mentees to have "a presence in the classroom as a way of gaining and maintaining the attention of students" (Participant 1) and to "be consistent, concise and constant as children crave rules and routines, and they work best in these conditions" (Participant 14). Apart from thoughtful planning, developing positive relationships was considered a cornerstone for managing students and so it was emphasised that they need to build "relationships as you have to be able to communicate and want to get to know your students... to be successful" (Participant 17). Participant 18 claimed "if they can't do this (build relationships) then it is hard to really know your students enough for appropriate behaviour management, differentiation". These comments presented strong connections between the personable attributes and classroom practices, which was also indicated in planning for differentiated learning.

Know students for differentiated learning. One fifth of the participants wrote that knowing the students will aid in planning for students' differentiated learning, to illustrate: "getting to know the students, learning styles, personalities" (Participant 4), "where they are at, why they are at this stage, and where you want to take them" (Participant 14), and "the quicker they know the kids the better they will be able to adapt correct strategies for best learning" (Participant 7). From this point, lessons can be well structured with an "introduction, activities and conclusion (to) provide a range of teaching strategies to cater for different learning styles in the classroom" (Participant 5). So it was considered necessary to "make decisions based on students' learning outcomes (about their teaching strategies/styles)" (Participant 2, parenthesis included). Hence, knowing students for planning differentiated learning activities was shown to be a desirable mentee practice.

Content knowledge, adhering to policies, observation and reflection. Three participants highlighted the importance of the mentee having content knowledge for teaching, to "research and investigate thoroughly - to enable the correct content to be taught as well as how it is best taught" (Participant 15) and six participants outlined the importance of mentees getting familiar with policies, for instance, "awareness of subject content (research) and school policies - knowledge of the context the student will be involved in" (Participant 13). Indeed, the "importance of school/department policies" (Participant 10) and "following school, uni, Ed Queensland policies and guidelines" (Participant 11) were considered essential practices for not only content knowledge but all areas of involvement in the school. Finally, there were comments about the mentee having observational skills to ensure observations are purposeful and "interpreting good practices throughout all school contexts" (Participant 9) as a result of informed observations. There were comments around "consistent and 
structured reflection (self and of mentor) on classroom/school strategies and processes" (Participant 20) and having a "questioning attitude" where the mentee needs to clarify understandings. It was noted that questioning can aid reflections and lead the mentee towards re-defining teaching practices.

\section{Focus Group Discussions}

These 25 participants were placed into six focus groups and a digital audio recorder was placed on the table at each group; hence their identification as individual participants was not ascertained during these recordings. They discussed mentee attributes and practices needed for involvement in learning how to teach. Their discussions elaborated on many of the desirable attributes and practices they had previously written. In particular, they advised that mentees need to be risk takers and develop resilience when teaching does not go according to plan. Indeed, this was a common theme among the groups, as noted by Group 1 in the following discussion.

Participant A: Having the confidence to have a go and sometimes negatives can turn into positives. That is, sometimes if you fail at something, you actually learn more than if you just have success every time. So I was trying to word that. But if you have a disaster in a lesson.

Participant B: I always tell my students that they don't have a lesson that goes poorly or really, if they fail at a particular lesson, so long as you learn through that, I remember things that I did on prac that I never, ever did in my teaching because you learn from that mistake.

Participant C: But I still have days like that when I go to lunch and I then think and go my god I will never attempt that again. Laugh.

Participant B: Teachers should be risk takers and encourage students to learn in different ways so that's a good thing. It's just when they don't always go smoothly. That's a learning experience.

All groups outlined the need for mentees to be personable and caring, especially as teaching requires building relationships. The following discussion from Group 2 participants illustrates these desirable attributes and practices.

Participant D: I said enthusiasm, lifelong learner, personable, caring, considerate, so I kind of bumped them into the groups that matched. learning.

Participant E: It's the caring nature as well. That caring extends beyond what they're actually

Participant D: I think that comes into personable.

Participant F: I said personal, caring, being able to build an authentic relationship to communicate with others.

Yet, the conversation in Group 2 reverted towards the need for mentees to be resilient:

Participant D: I wrote don't get too bogged down in the day to day, it can be an overwhelming kind of a job. And if you're feeling negative, or negativity, find ways to reinvigorate. Because as soon as you're not liking it, it's a hell of a job. And you have a duty to your students just to always remind them that it's not about you, it's about your kids.

Desirable attributes and practices for mentees continued to focus on building resilience within the teaching profession. Developing a "sense of humour because you're going to have your good days and your bad days and if you can't laugh at yourself, then you're not going to last very long in the profession" was received as an agreed attribute. Although confidence building was also recognised as a desirable attribute, it needed to be kept in check to ensure overconfidence does not negate the level of skill. Two of the four participants in one group discussed the confidence issue: 
Participant G: Building your confidence in the staffroom and the classroom also enables the student to explore various strategies and also have that presence because I have some student teachers who just don't have the confidence and they don't have the presence and the kids walk all over them.

Participant H: I struggle with that, I was thinking about that too but then I thought at the same time, you don't want them to be at the point where they think they know everything. So I was thinking that, but at the same...

Participant G: But they have to be confident enough to get in there.

Participant $\mathrm{H}$ : Yeah but not to the point where they think they know everything.

Participant G: Yeah it could be looked at that way.

Participant H: Not over confident but confident to be comfortable in the situation. And just having that, being able to get that presence.

\section{Best Advice to Mentees}

In an attempt to further clarify desirable mentee attributes and practices these experienced teachers $(\mathrm{n}=25)$ were asked to provide their "best advice to a mentee", which aided in understanding more about the attributes and practices for mentees. The advice generally focused on establishing positive relationships, seeking opportunities, working with mentor's feedback, developing a teaching identity and being a role model, as illustrated in some of the following comments:

- Approach the task with an open mind and to learn all you can from the experience. Decide is this what I want to do, and if it is then do all you can to be the best you can be and allow your character to flourish (Participant 6).

- Preservice teachers, teachers and other educators alike need feedback to grow and develop better practices; we are all in it for the same reason (Participant 8).

- You're a public figure so uphold the professional stature as you grow and learn from your peers (Participant 9).

- Be yourself (Participant 7) because if you adopt a fake persona the students will see right through it (Participant 1).

Yet, the most prominent advice from these experienced teachers continued to focus on the mentees developing resilience within the teaching profession, for instance: "No one is perfect. Most students do want to learn and even when you feel beaten, persist. Talk to others; don't focus on negative, look for positive and act on it" (Participant 3), "Sometimes negatives can turn into positives, i.e. our failures can sometimes teach us more than our success can" (Participant 11), and "Always keep the end in sight. Don't get too bogged down in the day to day; remain positive. If you're feeling negativity find ways to reinvigorate as you have a duty to your students" (Participant 16). Resilience was noted as a way to "learn from your mistakes and try to find some humour and positiveness in each day" (Participant 17) with references to resilience not only as a result of classroom teaching but also interacting with other people within the school community: "you will find schools are a community and there are different personalities and a hierarchy" (Participant 18). Figure 1 summarises mentee attributes and practices that teachers considered desirable for mentees' involvement in school experiences.

\section{Discussion}

Experienced teachers in this qualitative study identified desirable attributes and practices for mentees when engaging in professional school experiences (see Figure 1). Responses indicated little doubt that teaching required high levels of interaction for developing positive relationships; hence developing personable attributes that lead towards facilitating such relationships was considered desirable. These 
teachers identified particular skills associated with being personable, including attentive listening, highlevel communication skills, and having a sense of humour. Importantly, being personable contributes to developing positive relationships, which can increase student engagement in learning (Pianta, Hamre, \& Allen, 2012). Teaching is a relationship-based career, where teachers interact continually throughout any given school day, not only with school students but also with colleagues, parents and the wider community. Consequently, mentors in this study recognised that mentees required very specific attributes that would help them to become part of the educational system.

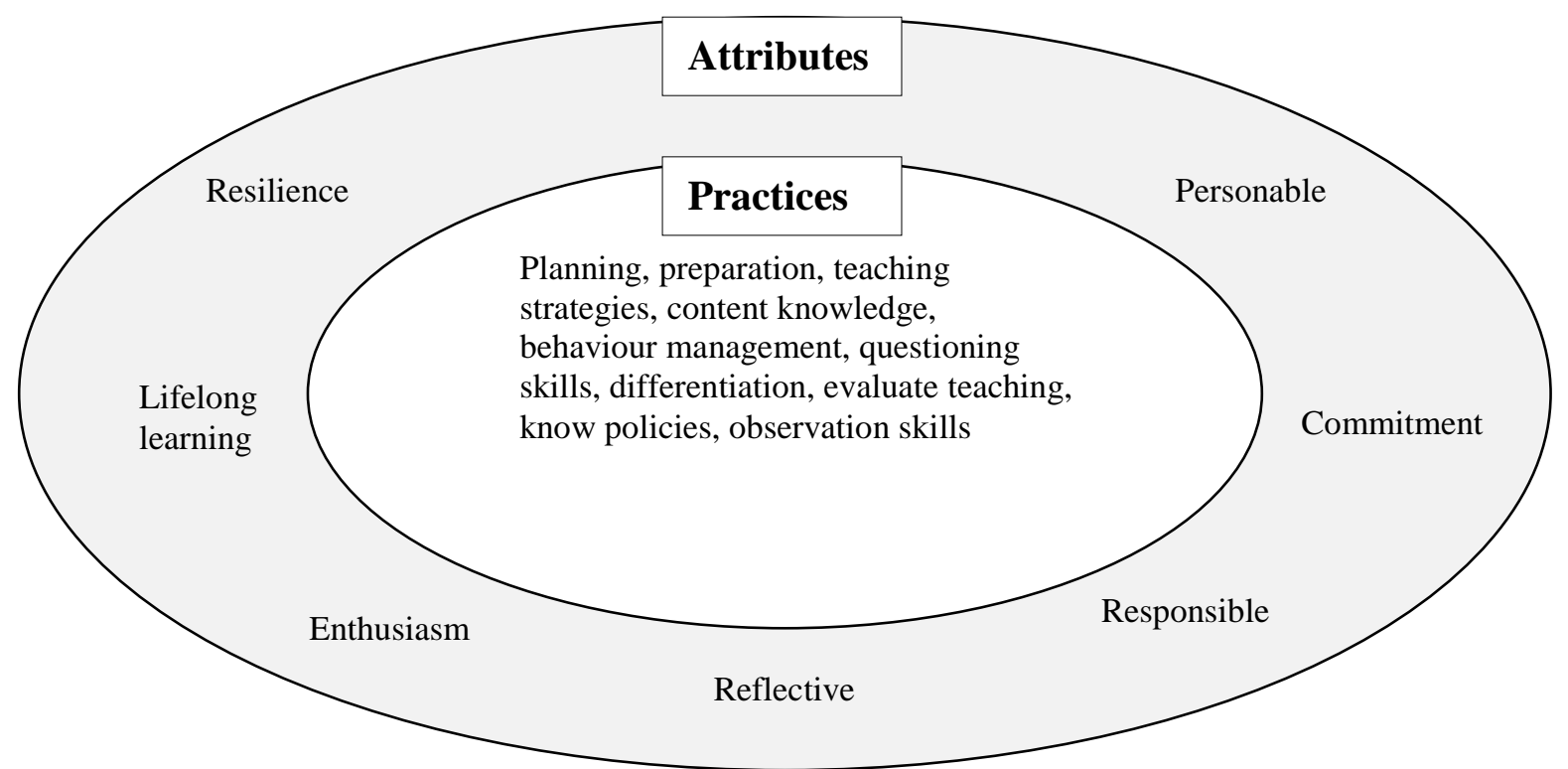

Figure 1. Desirable Mentee Attributes and Practices

Developing resilience, as a desirable attribute, attempts to negate unfavourable experiences and allows mentees to "bounce back". Developing resilience was noted as a possible solution for addressing stressful situations, particularly as teachers continue along their career paths (see also Howard \& Johnson, 2004). Brodkin and Coleman $(1996,28)$ define resilience as "the ability to develop coping strategies despite adverse conditions, positive responses to negative circumstances, and a protective shield from continuous stressful surroundings". A sign of resilience is sustaining educational purposes after stressful situations that are generally linked to personal, relational or organisational issues $(\mathrm{Gu} \&$ Day, 2012). It was clearly articulated in this study that mentees need resilience as they can receive critical feedback, they can have "bad days", and they can question themselves about their chosen vocation. In some way, teacher resilience may serve to forge stronger teacher identities and career commitment.

As indicated in this study, preservice teachers need to show commitment and enthusiasm to enter and remain in the teaching profession (e.g. see Thompson, Turner, \& Nietfeld, 2011). Investing in professional capital, such as having mentor teachers to guide preservice teachers, can lead towards enhancing commitment and dedication to teaching as a career (Hargreaves \& Fullan, 2012). However, 
will preservice teacher commitment and enthusiasm be sufficient to sustain career involvement? Bruinsma and Jansen's (2010) study suggests that career decisions can be influenced by initial motivations to enter teaching that may be related to remaining in the profession, yet developing resilience can also assist to upturn negative experiences. Other attributes mentioned in this study such as being a lifelong learner, responsible, and reflective appear to align with the teaching profession. For example, critical self reflection can transform practices for the advancement of teaching and learning (Schön, 1987).

The desirable mentee practices noted by these teachers such as planning, preparation, behaviour management, and having a bank of teaching strategies (see Figure 1) are discussed in numerous books on effective teaching (e.g. Muijs \& Reynolds, 2011) and through various studies on teaching (see the journal Teaching and Teacher Education). In addition, these teachers considered knowledge of university and school policies as practices that would assist the preservice teachers' engagement in schools, particularly as policies not only guide what should happen in schools but can also have legal implications when deviating from these directives. Some of these teachers wanted their mentees to have observation skills for understanding classroom contexts and pedagogical decisions with an ability (and courage) to question the mentor about teaching and learning. There were 14 primary teachers and 11 secondary teachers in this study for which data indicated no differences between primary and secondary school involvement when it came to identifying desirable mentee attributes and practices (Figure 1). For example, primary and secondary teachers claimed that the attributes of being personable, enthusiastic, reflective, and resilient pertained to both primary and secondary settings and, although the desirable practices would be adjusted for grade appropriateness, practices such those noted in Figure 1 are consistently reinforced in the literature for primary and secondary teachers (e.g. the journal Teaching and Teacher Education).

More qualitative and quantitative studies are required to investigate models on attributes and practices for mentees. To date, the research has been considerably one sided with most studies focused on the mentors' attributes and practices (e.g. Hudson, 2010). Yet models on desirable attributes and practices for mentees may help mentees to interact more purposefully with students, with their mentor teachers and within school systems. Further research needs to include mentees' views on desirable attributes and practices and involve other key stakeholders (e.g. school executives, department of education staff, university personnel). Mentees' attributes and practices must be realistic and target the preservice teachers' "zone of proximal development" (e.g. Vygotsky, 1978); hence studies are required to investigate preservice teachers' attributes and practices at different university levels (i.e., first year to final year) with research coordinated between universities to provide a holistic and possibly national view of such attributes and practices for mentees, particularly where there are national curricula documents. For instance, a quantitative study may undertake the use of attributes and practices indicated in qualitative research to devise surveys that can lead towards factor analysis and a possible model for mentees' engagement in schools with new curricula documents.

More research is needed around each of these desirable attributes and practices indicated in this study to understand how preservice teachers can develop these skills. For example, if investigating the attribute of "enthusiasm", various research questions can be studied such as: What constitutes enthusiasm for a mentee? How does the mentee's enthusiasm assist in learning to teach or for interacting with others? How do mentors respond to the mentees' enthusiasm? What is genuine enthusiasm for teaching? Determining mentees' desirable attributes and practices may assist mentees to formulate teaching identities; however, despite articulating desirable attributes, there is a risk of being too prescriptive with a list of attributes for mentees that may reduce their capacity to realise their own natural teaching identities. Therefore, attributes for mentees suggested in this study provide broad 
guidelines but mentees will need to ensure they have sufficient flexibility to discover a teaching identity that will be of most use for their teaching careers.

\section{Conclusion}

The desirable attributes identified in this study appeared to be commonly held views of these experienced teachers, who highlighted commitment, enthusiasm, developing resilience and being personable as crucial for the teaching profession. The practices identified by the mentor teachers have commonplace agreement in many other studies. Mentoring and teaching are learnt skills, particularly with ongoing educational reform measures that necessitate innovative ways for the enactors of reform (classroom teachers and preservice teachers) to work together. Indeed, mentors and mentees need guidance based on research evidence to assist them in working together effectively; therefore investigating ways for mentees to interact more purposefully may provide the necessarily scaffolding they require in their formative stages of development in school settings. Mentees need positive teaching experiences to grow professionally and for generating greater teacher self efficacy (Bandura, 1986; Bruinsma \& Jansen, 2010); consequently mentors' articulations of desirable attributes and practices may help mentees to achieve their much sought after positive teaching experiences. The desirable attributes and practices indicated in this study may be used within a mentee's guidebook before entering a school experience with further direction from university personnel to assist them in understanding how these attributes and practices are enacted.

\section{Acknowledgements}

This work was conducted within the Teacher Education Done Differently (TEDD) project funded by the Australian Government Department of Education, Employment and Workplace Relations (DEEWR). Any opinions, findings, and conclusions or recommendations expressed in this paper are those of the authors and do not necessarily reflect the views of the DEEWR. I would like to acknowledge the work of Dr. Sue Hudson as Project Leader.

\section{References}

Bandura, A. (1986). Social foundations of thought and action: A social cognitive theory. Englewood Cliffs, NJ: Prentice Hall.

Bradbury, L. U., \& Koballa, T. R. Jr. (2008). Borders to cross: Identifying sources of tension in mentorintern relationships. Teaching and Teacher Education: An International Journal of Research and Studies, 24, 2132-2145.

Brodkin, A. M, \& Coleman, M. (1996). What makes a child resilient? How you can help kids succeed against the odds. Instructor, 105: 28-29.

Bruinsma, M., \& Jansen, E. P. W. A. (2010). Is the motivation to become a pre-service teacher related to pre-service teachers' intentions to remain in the profession? European Journal of Teacher Education, 33, 185-200.

Creswell, J. W. (2012). Educational research: Planning, conducting, and evaluating quantitative and qualitative research (4th Edn.). Upper Saddle River, NJ: Pearson Education Inc.

Ensher, E. A., \& Murphy, S. E. (2011). Power mentoring how successful mentors and proteges get the most out of their relationships. John Wiley \& Sons Inc., http://www.qut.eblib.com.au/patron/FullRecord.aspx?p=239438 (accessed August 21, 2013). 
Evertson, C. M., \& Smithey, M. W. (2000). Mentoring effects on proteges' classroom practice: An experimental field study. Journal of Educational Research 93, 294-304.

Gu, Q., \& Day, C. (2011). Challenges to teacher resilience: conditions count. British Educational Research Journal, 39, 22-44.

Hargreaves, A, \& Fullan, M. (2012). Professional capital transforming teaching in every school. New York, New York: Teachers College Press.

Hobson, A. J., Ashby, P., Malderez, A., \& Tomlinson, P. D. (2009). Mentoring beginning teachers: What we know and what we don't. Teaching and Teacher Education 25, 207-216.

Howard, S., \& Johnson, B. (2004). Resilient teachers: Resisting stress and burnout. Social Psychology of Education, 7, 399-420.

Hudson, P. (2010). Mentors report on their own mentoring practices. Australian Journal of Teacher Education, 35, 30-42.

Iancu-Haddad, D., \& Oplatka, I. (2009). Mentoring novice teachers: Motives, process, and outcomes from the mentor's point of view. New Educator 5, 45-65.

Jones, M., \& Straker, K. (2006). What informs mentors' practice when working with trainees and newly qualified teachers? An Investigation into mentors' professional knowledge base. Journal of Education for Teaching, 32, 165-84.

Le Cornu, R., \& Ewing, R. (2008). Reconceptualising professional experiences in pre-service teacher education... Reconstructing the past to embrace the future. Teaching and Teacher Education: An International Journal of Research and Studies, 24, 1799-1812.

Longworth, N. (2013). Lifelong learning in action: Transforming education in the 21st century. Routledge.

Maynard, T. ( 2000). Learning to teach or learning to manage mentors? Experiences of school-based teacher training. Mentoring and Tutoring 8, 17-30.

McCann, T. M., \& Johannessen, L. (2009). Mentoring Matters: Working with Student Teachers. English Journal, 99, 114-117.

Monaghan, J., \& Lunt, N. (1992). Mentoring: Person, process, practice, and problems. British Journal of Educational Studies, 40, 248-263.

Muijs, D., \& Reynolds, D. ( 2011). Effective teaching: Evidence and practice. Los Angeles, CA: Sage.

Pianta, Robert C, Bridget K. Hamre, and Joseph P. Allen. 2012. Teacher-student relationships and engagement: Conceptualizing, measuring, and improving the capacity of classroom interactions. In Handbook of research on student engagement, ed. Sandra L. Christenson, Amy L. Reschly, and Cathy Wylie, 365-386. US: Springer.

Rajuan, M., Beijaard, D., \& Verloop, N. (2008). Student teachers' perceptions of their mentors as internal triggers for learning. Teaching Education, 19. 279-292.

Schön, D. A. (1987). Educating the reflective practitioner: Toward a new design for teaching and learning in the professions. San Francisco: Jossey-Bass.

Sempowicz, T., \& Hudson, P. (2011). Analysing mentoring dialogues for developing a preservice teacher's classroom management practices. Australian Journal of Teacher Education, 36, http://ro.ecu.edu.au/ajte/vol36/iss8/1 (accessed August 2, 2013).

Sempowicz, T., \& Hudson, P. (2012). Mentoring preservice teachers' reflective practices to produce teaching outcomes. International Journal of Evidence Based Coaching and Mentoring, 10, 5264.

Thompson, M. M., Turner, J. E., \& Nietfeld, J. L. (2011). A typological approach to investigate the teaching career decision: Motivations and beliefs about teaching of prospective teacher candidates. Teaching and Teacher Education, 2, 324-335

Vygotsky, L. S. (1978). Mind in society. Cambridge, MA: Harvard University Press.

(C) 2013, European Journal of Educational Research, 2(3), 107-119 
Ward, M. J., \& Wells, T. J. (2003). Guests in the classroom: Top ten tips for preservice teachers. Kappa Delta Pi Record, 40, 42-44. 